\title{
Heat Transfer Model to Predict Human Skin Temperature under Comfort Level by using Bioheat Equation
}

\author{
https://doi.org/10.3991/ijoe.v15i10.10876 \\ Zaina Norhallis Zainol ${ }^{(凶)}$, Masine Md. Tap, \\ Haslinda Mohamed Kamar, Nazri Kamsah \\ Universiti Teknologi Malaysia, Johor Bahru, Malaysia \\ zai_norhallis@yahoo.com
}

\begin{abstract}
Thermal comfort is the human subject perceived satisfaction to the environmental condition. The human comfort level is affected by skin temperature. Currently to determine the human skin temperature by using human experiment in a controlled environment. However, the experiment is very rigorous and exhaustive. This study was conducted to predict human skin temperature under comfort level with using the finite element method and the bioheat equation. The bioheat equation is used to predict the initial value of human skin temperature with the influence of the metabolic heat generation and the blood perfusion. It is discovered the skin temperature of the human subject experiment fluctuates. However, the result obtained from the model remains unchanged until the simulation ends. The predicted results from the model were well in agreement with the experimental results with an acceptable error of $1.05 \%$.
\end{abstract}

Keywords-Heat Transfer, Thermal Comfort, Bioheat

\section{Introduction}

Thermal comfort is the person subject perceive satisfaction towards the surrounding environment conditions. The thermal environment is assessed by a subjective evaluation according to the Olesen and Parsons [1] are based on the predicted mean vote known as the PMV model that aims to minimize the percentage of dissatisfaction towards the surrounding. The indoor environment can be maintained according to the human clothing level and body metabolic heat generation. It is also relate to the human physical activities. The current study assesses thermal comfort of indoor spaces by using the thermal balance between the human body and the surrounding. Previously the thermal comfort model introduced by Ferreira and Yanagihara [2], Fanger [3] Predicted Mean Vote (PMV), Gagge, Stolwijk [4] standard effective temperature (SET) and Höppe [5] physiological equivalent temperature (PET). These models were developed without considering the human metabolic heat rate and the blood perfusion that affect the subject comfort level [6]. Instead, the models considered the thermal parameters, such as air velocity and indoor radiant field. The models were also based 
on the human subjective perception and not human physiology, such as skin temperature or the human core temperature. These models were incapable of predicting human physiology in a complex environment. According to Lai, Guo [7], the PMV model overestimated the thermal sensation by a factor of 1.3. This may be due to incorrect estimation of the single body without considering the blood perfusion and metabolic heat generation.

Blood perfusion is important as it is affected by physical activities and the surrounding environment [6]. The blood perfusion of the human body is influenced by the human body thermoregulation [8]. Consequently, skin temperature fluctuates due to blood perfusion and metabolic heat generation. The overall thermal sensation and skin temperature show a linear relation, which means the overall human thermal sensation can be reflected by skin temperature [9]. Therefore, these factors must be considered to determine the accuracy of skin temperature prediction under comfort level. Blood perfusion is a decisive part of the human thermal functions. About $50 \%-80 \%$ of the heat flow in the tissue is carried out by blood flow [10]. Skin temperature under comfort level can be predicted by using Pennes bioheat equation with the consideration of clothing. Bioheat equation is the mathematical model for heat transfer in human tissue called the bioheat equation. The effect of blood flow on heat transfer was modeled as heat sink or source whose magnitude is proportional to the volumetric perfusion rate and difference between arterial and venous temperatures [11, 12].

Currently there are other models that consider blood perfusion to predict human skin temperature [13, 14]. Stolwijk [15] developed a multi-segmented mathematical model of the entire human body. He used a spherical head and five cylindrical segments to represent the human body that mainly consists of the trunk, arms, hands, legs, and feet. Each segment was divided into four layers, i.e. lumped layers, muscle, fat and tissue. It was also connected to the blood flow of a circulatory system to regulates the body heat There are also a few researchers that developed models based on the Berkeley comfort model $[6,16,17]$ by increased the number of segments, improved the blood flow model including the counter flow heat exchange at each segment and added clothing insulations. However, the models were too complex and exhaustive, which required high computer power to solve the calculations.

In this study, a new practical approach that focused on the human arm was developed to predict the human skin temperature under comfort level using the finite element method and bioheat equation. The study aimed at identifying the interaction of the surrounding condition with the human physiology without conducting experiment on human subjects.

\section{Methodology}

The analysis began by solving the bioheat equation, which is merely a steady conduction heat transfer in living tissue. The equation also included the heat generated by metabolic and blood perfusion rates. The equation was used to solve heat transfer at the muscle layer to determine the temperature between the skin layers and muscle, which in turn was used as the boundary condition in the finite element analysis. The 
ANSYS software Version 14.0 was used as a tool to perform the finite element analysis under transient conditions.

\subsection{The mathematical model}

Pennes [10] introduced a modification of the heat transfer in living tissue by adding the metabolic heat generation and heat exchange of thermal energy of flowing blood and the surrounding tissue. Both factors can be identified as heat sources in the heat transfer equation as follows:

$$
\frac{d^{2} T}{d x^{2}}+\frac{q_{m}+q_{p}}{k}=0
$$

Where, $q_{m}$ and $q_{p}$ are the metabolic and perfusion heat rates, respectively. The thermal conductivity, $\mathrm{k}$ is assumed to be constant.

$$
\dot{q_{p}}=w \rho_{b} c_{b}\left(T_{a}-T\right)
$$

Equation 2 represents the heat transfer rate of blood flowing in small capillaries. The inlet (arterial temperature) and exit temperatures of the blood are denoted as Ta and $\mathrm{T}$, respectively. The rate at which the skin tissue layer gains the heat is the rate at which blood loses heat. The blood perfusion rate is denoted as $\mathrm{w}(\mathrm{m} 3 / \mathrm{s}$ of the volumetric blood flow) while $\rho_{\mathrm{b}}$ and $\mathrm{c}_{\mathrm{b}}$ are the blood density and specific heat, respectively.Consider a human body that has a muscle thickness, $\mathrm{Lm}$ of $34.2 \mathrm{~mm}$ and skin fat thickness, Lsf of $12.08 \mathrm{~mm}$ [18] as illustrated in Fig. 1. The surface area of the skin is estimated to be $1.8 \mathrm{~m} 2$ [19]. The core body temperature, Tc and arterial temperature, $\mathrm{Ta}$ are both assumed to be $37^{\circ} \mathrm{C}$. The metabolic heat generation rate of a person in a sedentary situation at the upper arm, $\mathrm{q}_{\mathrm{m}}$ is $684 \mathrm{~W} / \mathrm{m} 3$ [20]. The radiation coefficient, $\mathrm{hr}$ is $5.49 \mathrm{~W} / \mathrm{m} 2 . \mathrm{K}$. The surrounding temp, $\mathrm{T}_{\infty}$ is assumed to be $30^{\circ} \mathrm{C}$. Table 1 shows the material properties of the human muscle, skin and blood.

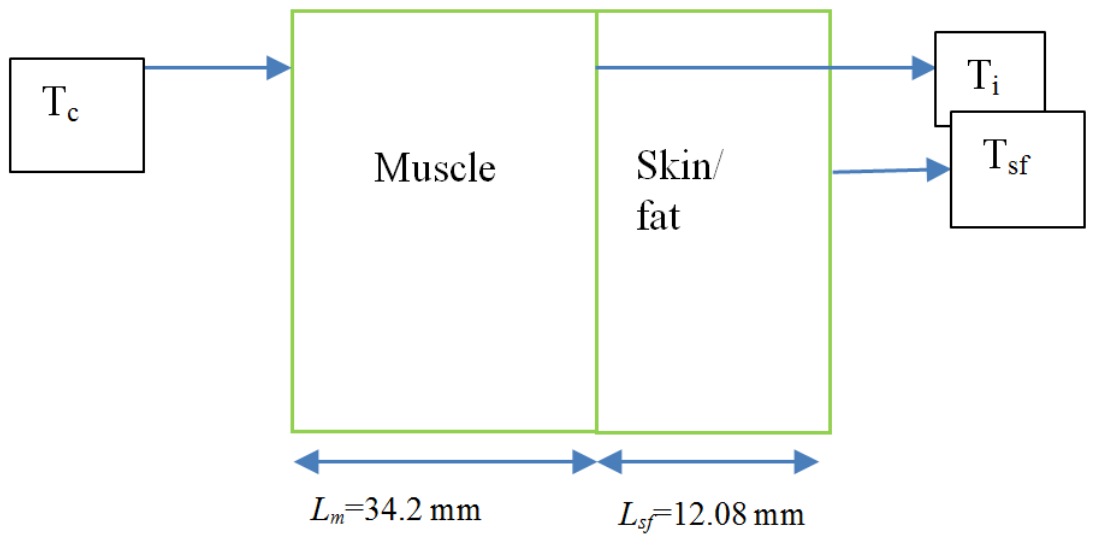

Fig. 1. The bioheat model. 
Table 1. The properties of the human muscle, skin and blood [21]

\begin{tabular}{|l|c|}
\hline \multicolumn{1}{|c|}{ Properties } & Value \\
\hline Blood density [19] & $1060 \mathrm{~kg} / \mathrm{m}^{3}$ \\
\hline Blood specific heat [19]. & $3770 \mathrm{~K} / \mathrm{kg} . \mathrm{K}$ \\
\hline Blood perfusion rate [19]. & $1.25 \times 10-3 \mathrm{~s}^{-1}$ \\
\hline Muscle thermal conductivity [20] & $0.42 \mathrm{~W} / \mathrm{mK}$ \\
\hline Muscle density [20] & $1085 \mathrm{~kg} / \mathrm{m}^{3}$ \\
\hline Muscle specific heat capacity [20] & $3768 \mathrm{~J} / \mathrm{kg} . \mathrm{K}$ \\
\hline Skin fat thermal conductivity [22] & $0.293 \mathrm{~W} / \mathrm{m} . \mathrm{K}$ \\
\hline Skin fat emissivity [22] & 0.95 \\
\hline
\end{tabular}

The rate of heat transfer between the skin and the adjacent air can be described as:

$$
\dot{\mathrm{q}}=\frac{\mathrm{T}_{\mathrm{i}}-\mathrm{T}_{\infty}}{\mathrm{R}_{\mathrm{tot}}}
$$

Where, the total resistance, Rtot is:

$$
\begin{aligned}
\mathrm{R}_{\mathrm{tot}} & =\frac{\mathrm{L}_{\mathrm{sf}}}{\mathrm{k}_{\mathrm{sf}} \mathrm{A}}\left(\frac{1}{1 / \mathrm{h}_{\mathrm{r}} \mathrm{A}}\right)^{-1} \\
& =\frac{1}{\mathrm{~A}}\left(\frac{\mathrm{L}_{\mathrm{sf}}}{\mathrm{k}_{\mathrm{sf}}}+\frac{1}{\mathrm{~h}_{\mathrm{r}}}\right)
\end{aligned}
$$

The radiation, hr heat transfer coefficient of the air gap is $5.49 \mathrm{~W} / \mathrm{m} 2 . \mathrm{K}$.

The excess temperature at the boundary as given by [23] is:

$$
\begin{aligned}
& \theta(0)=T_{c}-T_{a}-\frac{q_{m}}{w \rho_{b} c_{b}}=\theta_{c} \\
& \theta\left(L_{m}\right)=T_{i}-T_{a}-\frac{q_{m}}{w \rho_{b} c_{b}}=\theta_{i}
\end{aligned}
$$

The prescribed temperature involving two boundary conditions as given by [23] is:

$$
\frac{\theta}{\theta_{c}}=\frac{\left(\theta_{i} / \theta_{c}\right) \sinh \widetilde{m} x+\sinh \widetilde{m}\left(L_{m}-x\right)}{\sinh \widetilde{m} L_{m}}
$$

The heat that is leaving the muscle is equal to the heat that is transferred through the skin/fat. The heat transfer rate at $\mathrm{Lm}$ is:

$$
\mathrm{q}_{\mid \mathrm{x}=\mathrm{Lm}}=-\left.\mathrm{k}_{\mathrm{m}} \mathrm{A} \frac{\mathrm{dT}}{\mathrm{dx}}\right|_{\mathrm{x}=\mathrm{Lm}}=-\left.\mathrm{k}_{\mathrm{m}} \mathrm{A} \frac{\mathrm{d} \theta}{\mathrm{dx}}\right|_{\mathrm{x}=\mathrm{Lm}}=-\mathrm{k}_{\mathrm{m}} \mathrm{A} \widetilde{\mathrm{m}} \theta_{\mathrm{c}} \frac{\left(\theta_{\mathrm{i}} / \theta_{\mathrm{c}}\right) \cosh \widetilde{\mathrm{m}} \mathrm{L}_{\mathrm{m}}-1}{\sinh \widetilde{\mathrm{m}} \mathrm{L}_{\mathrm{m}}}
$$

By combining Equation 3 and Equation 7, the surface temperature at muscle Ti is:

$$
\begin{gathered}
T_{i}=\frac{T_{\infty} \sinh \widetilde{m} L_{m}+k_{m} A \widetilde{m} R_{t o t}\left[\theta_{c}+\left(T_{a}+\frac{q_{m}}{w \rho_{b} c_{b}}\right) \cosh \widetilde{m} L_{m}\right]}{\sinh \widetilde{m} L_{m}+k_{m} A \widetilde{m} R_{t o t} \cosh \widetilde{m} L_{m}} \\
\text { Where, } \widetilde{m}=\sqrt{\frac{w \rho_{b} c_{b}}{k_{m}}}
\end{gathered}
$$


The skin/fat temperature, Tsf can be obtained by equating the heat transfer by conduction at the skin/fat layer to heat by radiation, $\mathrm{q}_{\mathrm{rad}}$ at the air layer. The heat that is transferred through the muscle layer, $\mathrm{q}_{\mid \mathrm{x}=\mathrm{Lm}}$ is equal to heat that is transferred through the skin/fat, $\mathrm{q}_{\text {cond } \mid \mathrm{x}=\mathrm{Lsf}}$ as follows:

$$
\begin{gathered}
\mathrm{q}_{\text {cond } \mid \mathrm{x}=\mathrm{Lsf}}=\mathrm{q}_{\mathrm{rad}} \\
\mathrm{q}_{\text {cond } \mid \mathrm{x}=\mathrm{Lsf}}=\mathrm{h}_{\mathrm{r}}\left(\mathrm{T}_{\mathrm{sf}}-\mathrm{T}_{\infty}\right)
\end{gathered}
$$

Therefore, the skin temperature is [21]

$$
\mathrm{T}_{\mathrm{sf}}=\frac{\mathrm{q}_{\operatorname{cond} \mid \mathrm{x}=\mathrm{Lsf}}+\mathrm{h}_{\mathrm{r}} \mathrm{T}_{\infty}}{\mathrm{h}_{\mathrm{r}}}
$$

\section{Validation and Verification}

Validation for the human body was compared with the study by [6]. The authors studied human physiology when exposed to partial and whole-body heating and cooling under a controlled environment. The skin temperature, core temperature, thermal sensation and thermal comfort responses were recorded for 19 local body parts and the whole body. The experiment was performed on 109 human subjects in a controlled climatic chamber. Thermocouples were attached to measure skin temperature at 28 locations for every $5 \mathrm{~s}$.

Fig. 2 shows the experiment by Huizenga, Zhang [6] on a human subject to determine the skin temperature of the human arm. This experiment was used for validation purposes to confirm that the outcome from the current research model is acceptable by the American Society of Heating, Refrigerating and Air-Conditioning Engineers [24]. Based on Huizenga, Zhang [6], the air sleeve encapsulated the subject's arm in a climatic chamber. It was used to control temperature, air velocity and humidity. The subject was wearing a long sleeved leotard made from cotton spandex. The air sleeve was attached to the borders of the subject's arm with Velcro strips sewn onto the leotard.

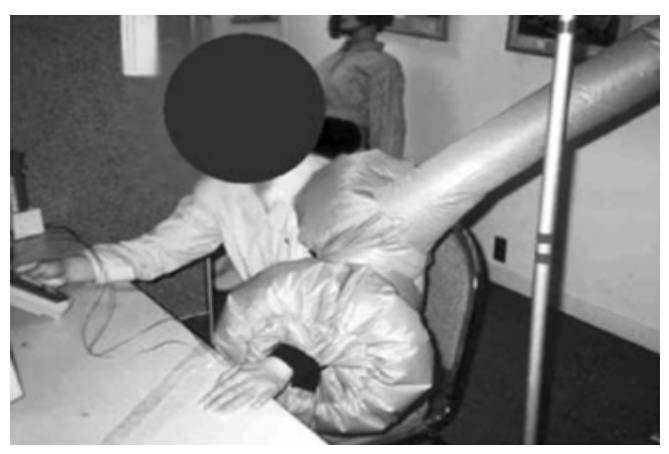

Fig. 2. The human subject encapsulated with an air sleeve in a climatic chamber as adapted from [6] experiment 
Fig. 3 shows the model geometry in 1-dimensional quarter geometry. It focuses on the human lower arm. The radius is $20 \mathrm{~mm}$, which represents the average human arm [6]. Fig. 3 also shows the quarter cylindrical geometry of this study that consists of three layers, namely the skin layer, air gap and clothing layer. The skin layer is placed at the inner most of the geometry. The air gap is in the gap between the skin and clothing layers. The material for the clothing layer is cotton spandex, also known as leotard. It is located at the outer layer geometry. Table 1 shows the model dimensions.

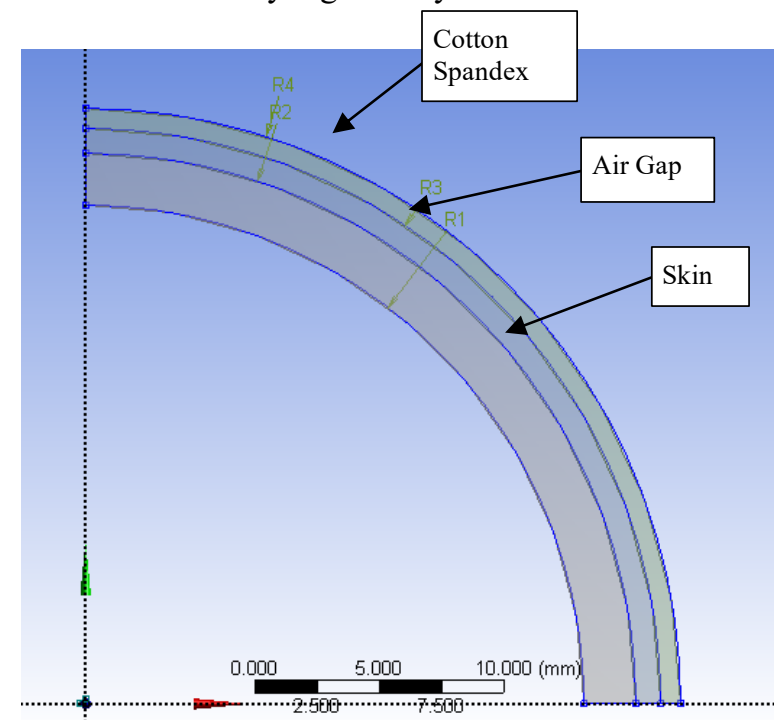

Fig. 3. The geometry of the study.

Table 2. Model dimensions.

\begin{tabular}{|l|c|}
\hline \multicolumn{1}{|c|}{ Layer } & Thickness (mm) \\
\hline Skin & 2.080 \\
\hline Air gap & 1.000 \\
\hline Cotton Spandex & 0.797 \\
\hline
\end{tabular}

Fig. 4 shows the boundary conditions specified in this model. The metabolic rate depends on the human physical activities. However, in this study, the human subject was in a sedentary state. The metabolic rate was $684 \mathrm{~W} / \mathrm{m} 2$. This value was applied in the bioheat equation to determine the initial value of the skin temperature. The inner layer skin temperature value was fixed at $36.8^{\circ} \mathrm{C}$ and located at the $\mathrm{D}$ layer that was obtained from Pennes' bioheat equation using Equation 9. The radiation was specified at the A layer, B layer and C layer with emissivity values of $0.8,0.8$ and 0.94 , respectively [25]. The coefficient of the natural convection was specified at the A layer by using Equation 10. The ambient temperature was $31.5^{\circ} \mathrm{C}$, based on [6]. The properties of the clothing material are specified in Table 2. The solution was at the skin layer, which is at the inner layer to observe the skin temperature variation against time. The simulation was simulated for 80 second. 


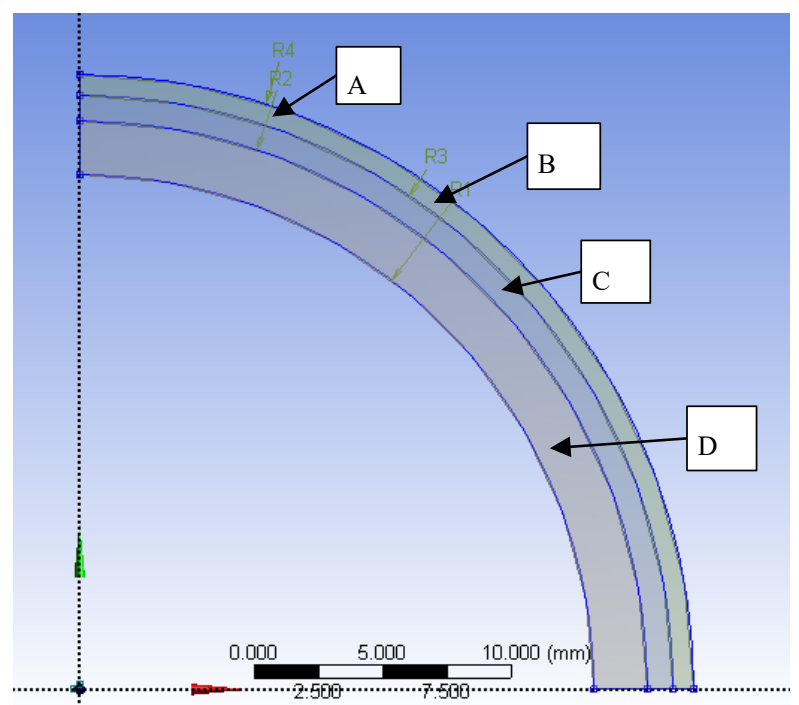

Fig. 4. The boundary condition in the finite element model.

Table 3. Properties of clothing material obtained from [25]

\begin{tabular}{|l|c|c|c|}
\hline \multicolumn{1}{|c|}{ Layers } & Skin & Cotton Spandex & Air Gap \\
\hline Density $(\mathrm{kg} / \mathrm{m} 3)$ & 1877 & 365 & 1.184 \\
\hline Emissivity & 0.95 & 0.8 & - \\
\hline Thermal conductivity (W/m.K) & 0.293 & 0.0294 & 0.02551 \\
\hline Specific heat capacity (J/kg.K) & 0.95 & $5.844 \times 10-4$ & 1007 \\
\hline
\end{tabular}

According to [23], the coefficient of the Nusselt number for a long horizontal cylinder can be determined by using the following equation:

$$
\mathrm{Nu}_{\mathrm{D}}=\left\{0.6+\frac{0.387 \mathrm{Ra}_{\mathrm{D}}^{\frac{1}{6}}}{\left[1+(0.559 / \mathrm{Pr})^{\frac{9}{16}}\right]^{\frac{8}{27}}}\right\}^{2}
$$

Where,

$\mathrm{Ra}_{\mathrm{D}}$ is the Rayleigh number for the long horizontal cylinder

Pr is the Prandtl number

[23] also stated that the Rayleigh number for a long horizontal cylinder can be obtained by using the following equation:

$$
\operatorname{Ra}_{\mathrm{D}}=\frac{\mathrm{g} \beta\left(\mathrm{T}_{\mathrm{s}}-\mathrm{T}_{\infty}\right) \mathrm{D}^{3}}{\mathrm{v} \alpha}
$$

Where,

$\mathrm{g}$ is the gravitational acceleration $(\mathrm{m} / \mathrm{s} 2)$

$\beta$ is the expansion coefficient $(\mathrm{K}-1)$

$\mathrm{T}_{\mathrm{S}}$ is the surface temperature $(\mathrm{K})$ 
$\mathrm{T}_{\infty}$ is the surrounding temperature $(\mathrm{K})$

$\mathrm{D}$ is the diameter $(\mathrm{m})$

$\mathrm{v}$ is the kinematic viscosity $(\mathrm{m} 2 / \mathrm{s})$

$\alpha$ is the thermal diffusivity $(\mathrm{m} 2 / \mathrm{s})$

The natural convection coefficient was determined by using the following equation, based on [23]:

$$
\mathrm{h}=\frac{\mathrm{k}}{\mathrm{D}} \mathrm{Nu} \mathrm{D}_{\mathrm{D}}
$$

Where,

$\mathrm{k}$ is the thermal conductivity $(\mathrm{W} / \mathrm{mK})$

$\mathrm{D}$ is the diameter $(\mathrm{m})$

$\mathrm{Nu}_{\mathrm{D}}$ is the Nusselt number for a long horizontal cylinder

Fig. 5 shows the meshing pattern used in the model. The type is quadrilateral uniform. The nodes at each interface were kept unbroken and continuous to promote physical interaction to ensure the calculation between the heat flux and material properties is correct to produce accurate results. The number of elements at each layer (from the outer to the inner layers) was kept constant. The aspect ratio for each element was fixed at 1:1 and the ratio decreased with the thickness of the layers.

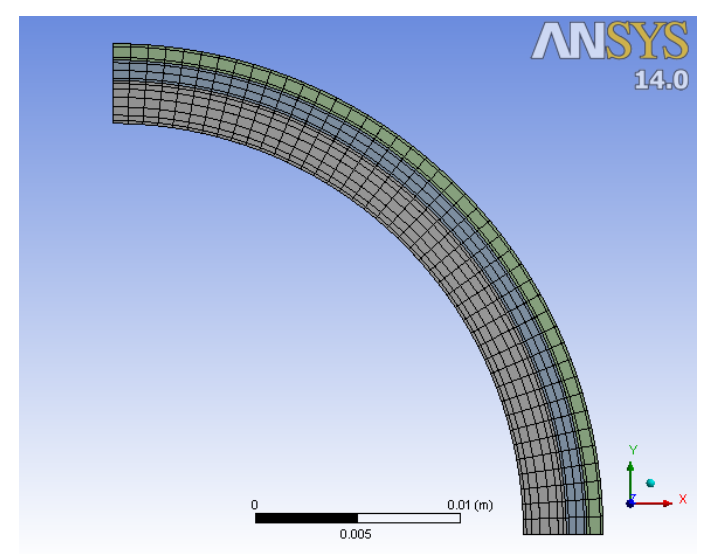

Fig. 5. Meshing pattern.

The simulation was performed under transient condition for a duration of $80 \mathrm{~s}$. The initial ambient temperature was specified at $31.5^{\circ} \mathrm{C}$ similar as prescribed by Huizenga et al. (2004). Fig. 6 shows the results of the model's Grid Independent Test (GIT). The GIT was conducted to determine the suitable number of elements to be used. The skin temperature was chosen as the reference parameter when performing the GIT. The number of elements used was increased until the skin temperature became stable and unchanged. Therefore, a total of 620 elements were used in the preceding finite element analysis. 


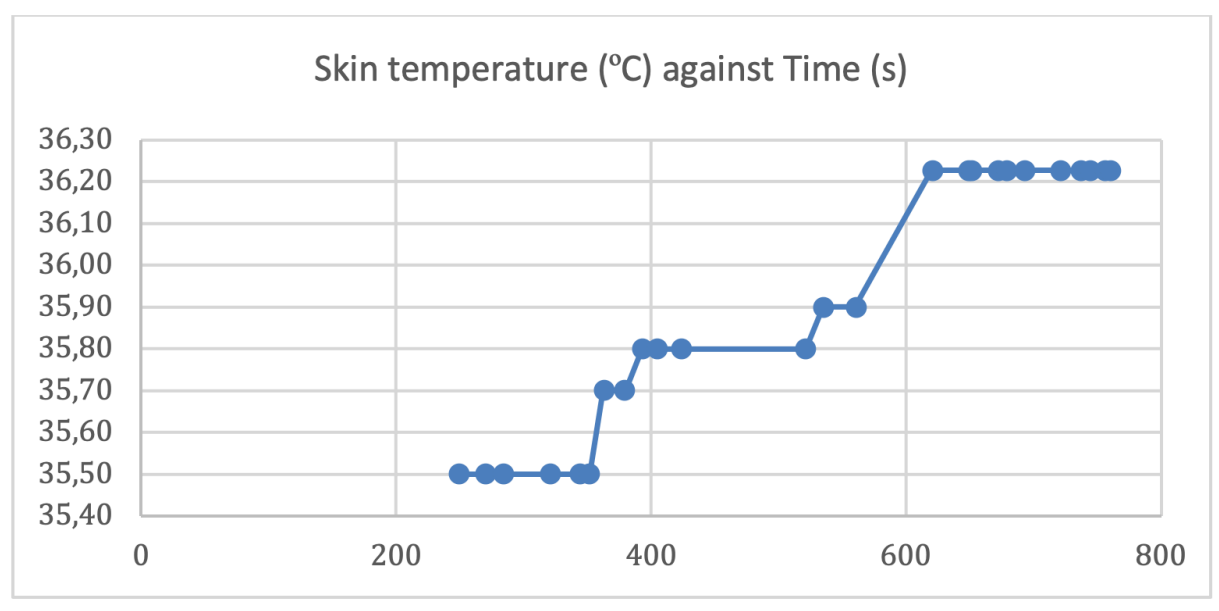

Fig. 6. The Grid Independent Test (GIT).

\section{$4 \quad$ Results and Discussion}

Fig. 7 shows the temperature contour inside the single-layered material. The outer clothing layer experienced the lowest temperature, i.e. $31.76^{\circ} \mathrm{C}$. It was found that the temperature changed gradually with the variation of layers from the skin surface to the outer layer of the clothing. The single-layered structure consisted of cotton spandex and air gap layers, causing the thermal resistance to grow, which led to a small increment of the skin temperature to around $37^{\circ} \mathrm{C}$ as compared to the outer layer temperature. Clothing plays an important role in thermal comfort. It regulates the skin temperature and exchanges the heat between the skin surface and the environment. The clothing is the causative factor in achieving thermal comfort [26, 27].

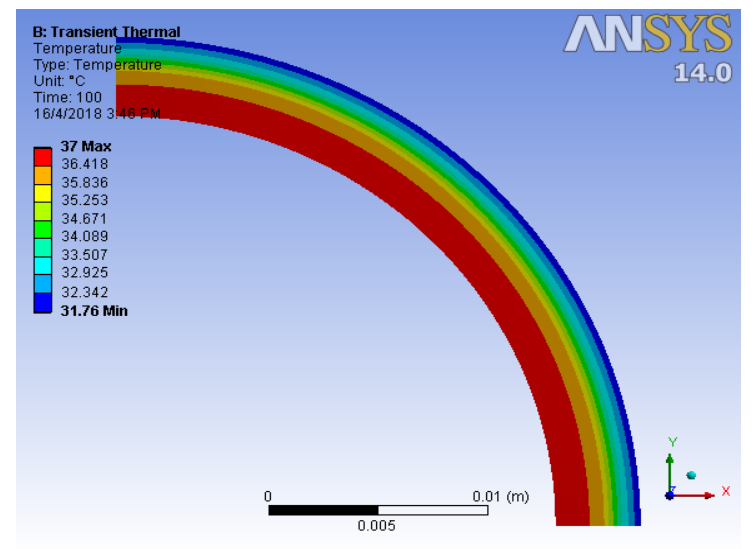

Fig. 7. Temperature contour of the model. 
Fig. 8 shows the plot against temperature. The time of the experiment was obtained from the model by Huizenga, Zhang [6] and the research model. The temperature started at an initial condition of $35.5^{\circ} \mathrm{C}$ and it gradually rose with time. The research model result showed the temperature remained constant at $\mathrm{t}=13 \mathrm{~s}$ until the simulation ended. However, in the experiment, the result showed that the skin temperature fluctuated and was unstable. Huizenga, Zhang [6] stated that the human skin temperature will fluctuate and remain unstable depending on physical activities and blood perfusion rate. Furthermore, in this model, the inner layer of the skin temperature and other variables remained constant throughout the simulation. This clearly explains why the skin temperature in the research model remained constant and unchanged starting from $\mathrm{t}=13 \mathrm{~s}$. The difference between the experiment and the research model was significantly small, i.e. approximately $1.05 \%$. According to [24], this error value is acceptable, as long as it is less than $20 \%$. Thus, the research model is reliable to predict human skin temperature.

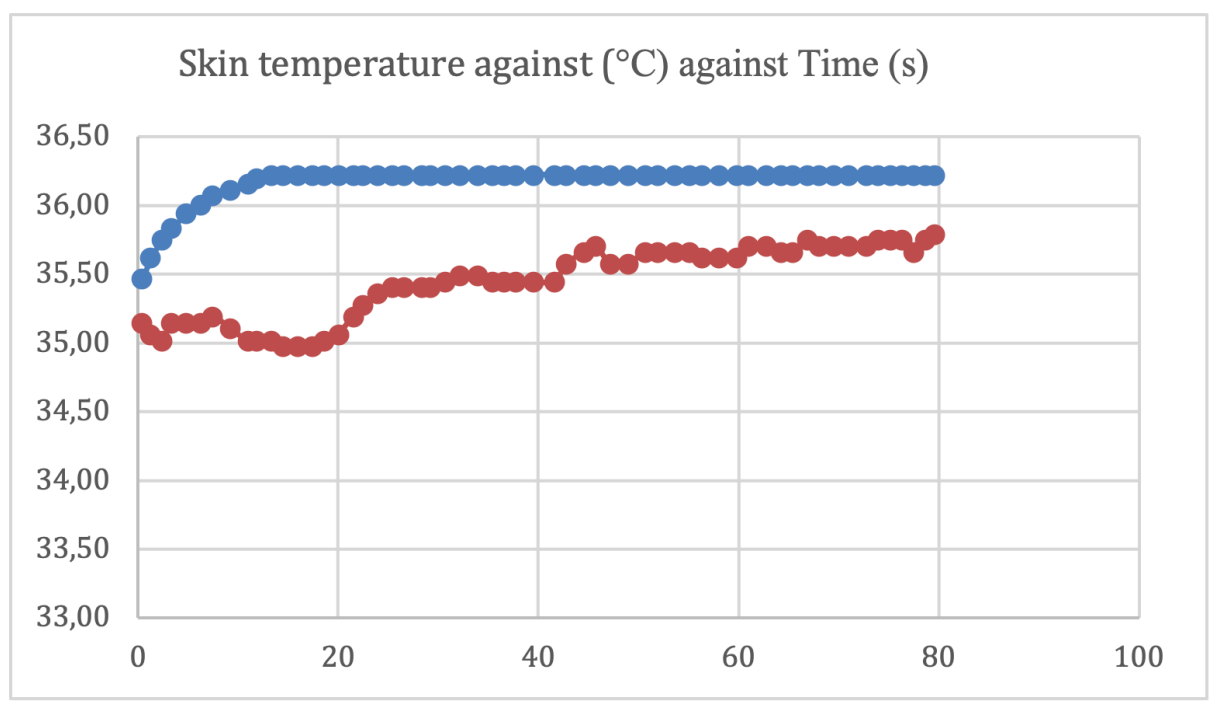

Fig. 8. Comparison between the research model and that of [6].

The thermal comfort is reflected by the core temperature and skin temperature [28]. Blood flow will influence skin temperature and the sensation of warmth or chillness, and consequently affects the feeling of comfort. The clothing material influences blood perfusion [29]. Therefore, there is a need to use the bioheat equation with the consideration of blood perfusion to determine the human skin temperature. Body extremities, such as the human arms, legs and feet are the most sensitive skin and it changes in adaptation to the thermal environment. They also play important roles in human thermoregulation [30]. The thermoregulatory process controls the blood flow of the human skin. It is vital to maintain the normal body temperature to achieve thermal homeostasis $[31,32]$. The fluctuation pattern from the experiment by [6] can be observed as the extremities were sensitive and affected the skin temperature. How- 
ever, the model was capable of predicting the human skin temperature with an insignificant difference of $1.05 \%$.

\section{Conclusion}

It is difficult to determine the human thermal comfort level as there are many variables that affect the skin temperature, such as environmental variables, clothing and the human skin physiology. It is observed that blood perfusion plays an important role in regulating the human body temperature towards the skin surface. The extremities of the human body are the most sensitive parts of thermoregulation. From the study, the use of the bioheat equation and finite element method were capable of predicting the skin temperature of the human arm. The predicted skin temperature value was in good agreement with the previous research. Therefore, the model was concluded as reliable to predict skin temperature under comfort level.

\section{Acknowledgement}

The authors would like to thank Universiti Teknologi Malaysia (UTM) for sponsoring the research (No. vot QJ1300000.2524.18H79) under the Research University Grant (GUP).

\section{$7 \quad$ References}

[1] Olesen BW, Parsons K. Introduction to thermal comfort standards and to the proposed new version of EN ISO 7730. Energy and buildings. 2002;34(6):537-48.

https://doi.org/10.1016/s0378-7788(02)00004-x

[2] Ferreira M, Yanagihara JI. A heat transfer model of the human upper limbs. International Communications in Heat and Mass Transfer. 2012;39(2):196-203.

https://doi.org/10.1016/j.icheatmasstransfer.2011.12.004

[3] Fanger PO. Thermal comfort. Analysis and applications in environmental engineering. Thermal comfort Analysis and applications in environmental engineering. 1970.

[4] Gagge A, Stolwijk J, Nishi Y. An effective temperature scale based on a simple model of human physiological regulatiry response. Memoirs of the Faculty of Engineering, Hokkaido University= 北海道大学工学部紀要. 1972;13(Suppl):21-36.

[5] Höppe P. The physiological equivalent temperature-a universal index for the biometeorological assessment of the thermal environment. International journal of Biometeorology. 1999;43(2):71-5, https://doi.org/10.1007/s004840050118

[6] Huizenga C, Zhang H, Arens E, Wang D. Skin and core temperature response to partialand whole-body heating and cooling. Journal of Thermal Biology. 2004;29(7-8):549-58. https://doi.org/10.1016/j.jtherbio.2004.08.024

[7] Lai D, Guo D, Hou Y, Lin C, Chen Q. Studies of outdoor thermal comfort in northern China. Building and Environment. 2014;77:110-8. https://doi.org/10.1016/j.buildenv.2014.03.026 
[8] Hirata K, Yutani M, Nagasaka T. Increased hand blood flow limits other skin vasodilation. Journal of Thermal Biology. 1993;18(5-6):325-7. https://doi.org/10.1016/03064565(93)90053-V

[9] Wang Z, He Y, Hou J, Jiang L. Human skin temperature and thermal responses in asymmetrical cold radiation environments. Building and environment. 2013;67:217-23. https://doi.org/10.1016/i.buildenv.2013.05.020

[10] Pennes HH. Analysis of tissue and arterial blood temperatures in the resting human forearm. Journal of applied physiology. 1948;1(2):93-122.

https://doi.org/10.1152/jappl.1948.1.2.93

[11] Zhu L, Xu LX, He Q, Weinbaum S. A new fundamental bioheat equation for muscle tissue - part II: temperature of SAV vessels. Journal of biomechanical engineering. 2002;124(1):121-32. https://doi.org/10.1115/1.1431263

[12] Weinbaum S, Xu L, Zhu L, Ekpene A. A new fundamental bioheat equation for muscle tissue: part I—blood perfusion term. Journal of biomechanical engineering. 1997;119(3):27888. https://doi.org/10.1115/1.2796092

[13] Lai D, Chen Q. A two-dimensional model for calculating heat transfer in the human body in a transient and non-uniform thermal environment. Energy and Buildings. 2016;118:11422. https://doi.org/10.1016/j.enbuild.2016.02.051

[14] Salloum M, Ghaddar N, Ghali K. A new transient bioheat model of the human body and its integration to clothing models. International journal of thermal sciences. 2007;46(4):37184. https://doi.org/10.1016/i.ijthermalsci.2006.06.017

[15] Stolwijk J. Mathematical model of thermoregulation. Physiological and behavioral temperature regulation. 1970.

[16] Tanabe S-i, Kobayashi K, Nakano J, Ozeki Y, Konishi M. Evaluation of thermal comfort using combined multi-node thermoregulation $(65 \mathrm{MN})$ and radiation models and computational fluid dynamics (CFD). Energy and Buildings. 2002;34(6):637-46. https://doi.org/10.1016/s0378-7788(02)00014-2

[17] Fiala D, Lomas KJ, Stohrer M. Computer prediction of human thermoregulatory and temperature responses to a wide range of environmental conditions. International Journal of Biometeorology. 2001;45(3):143-59. https://doi.org/10.1007/s004840100099

[18] Ogasawara R, Thiebaud RS, Loenneke JP, Loftin M, Abe T. Time course for arm and chest muscle thickness changes following bench press training. Interventional Medicine and Applied Science. 2012;4(4):217-20. https://doi.org/10.1556/imas.4.2012.4.7

[19] Onofrei E, Petrusic S, Bedek G, Dupont D, Soulat D, Codau T-C. Study of heat transfer through multilayer protective clothing at low-level thermal radiation. Journal of Industrial Textiles. 2015;45(2):222-38. https://doi.org/10.1177/1528083714529805

[20] Fiala D, Havenith G, Bröde P, Kampmann B, Jendritzky G. UTCI-Fiala multi-node model of human heat transfer and temperature regulation. International journal of biometeorology. 2012;56(3):429-41. https://doi.org/10.1007/s00484-011-0424-7

[21] Zainol ZN, Md Tap M, Mohamed Kamar H, editors. Application Bioheat Equation For Heat Transfer Model of Firefighter's Burn Injury. 2nd Asia International Multidisciplinary Conference AIMC 2018; 2018 12-13 May 2018; Johor Bahru https://doi.org/10.15405/epsbs.2019.05.02.15

[22] Cooper T, Trezek G. Correlation of thermal properties of some human tissue with water content. Aerospace medicine. 1971;42(1):24-7.

[23] Incropera FP, DeWitt DP, Bergman TL, Lavine AS. Fundamentals of heat and mass transfer. 6th ed. New York: John Wiley \& Sons; 2007.

[24] ASHRAE. Fundamentals. American Society of Heating, Refrigerating and Air Conditioning Engineers, Atlanta. 2001;111. 
[25] Lee S, Park C, Kulkarni D, Tamanna S, Knox T, editors. Heat and mass transfer in a permeable fabric system under hot air jet impingement. 2010 14th International Heat Transfer Conference; 2010: American Society of Mechanical Engineers. https://doi.org/10.1115/ihtc14-22695

[26] Zhong W, Xing MM, Pan N, Maibach HI. Textiles and human skin, microclimate, cutaneous reactions: an overview. Cutaneous and ocular toxicology. 2006;25(1):23-39. https://doi.org/10.1080/15569520500536600

[27] Havenith G, Holmér I, Parsons K. Personal factors in thermal comfort assessment: clothing properties and metabolic heat production. Energy and buildings. 2002;34(6):581-91. https://doi.org/10.1016/s0378-7788(02)00008-7

[28] Bulcao CF, Frank SM, Raja SN, Tran KM, Goldstein DS. Relative contribution of core and skin temperatures to thermal comfort in humans. Journal of Thermal Biology. 2000;25(12):147-50. https://doi.org/10.1016/s0306-4565(99)00039-X

[29] Gan Y, Cheng L, Ding X, Pan N. Blood flow fluctuation underneath human forearm skin caused by local thermal stimuli of different fabrics. Journal of Thermal Biology. 2010;35(7):372-7. https://doi.org/10.1016/j.jtherbio.2010.07.007

[30] Wang D, Zhang H, Arens E, Huizenga C. Observations of upper-extremity skin temperature and corresponding overall-body thermal sensations and comfort. Building and Environment. 2007;42(12):3933-43. https://doi.org/10.1016/j.buildenv.2006.06.035

[31] Charkoudian N, editor Skin blood flow in adult human thermoregulation: how it works, when it does not, and why. Mayo Clinic Proceedings; 2003: Elsevier.

https://doi.org/10.4065/78.5.603

[32] Joyner MJ. Cutaneous blood flow: uncomfortable in our own skin? American Journal of Physiology-Heart and Circulatory Physiology. 2009;296(1):H29-H30.

https://doi.org/10.1152/ajpheart.01184.2008

\section{Authors}

Zaina Norhallis Zainol is a scientific researcher at Universiti Teknologi Malaysia, Johor Bahru, Malaysia.

Masine Md. Tap is a Faculty of Mechanical Engineering Universiti Teknologi Malaysia, Johor Bahru, Malaysia

Haslinda Mohamed Kamar, is a Senior Lecturer of Department of ThermoFluids, Faculty of Mechanical Engineering, Universiti Teknologi Malaysia, Johor Bahru, Malaysia

Nazri Kamsah is a Faculty of Mechanical Engineering, Universiti Teknologi Malaysia, Johor Bahru, Malaysia

Article submitted 2019-04-13. Resubmitted 2019-05-26. Final acceptance 2019-05-30. Final version published as submitted by the authors. 